\title{
Contagion and risk premia in the amplification of crisis: evidence from Asian names in the global CDS market
}

\author{
Don $\mathrm{H} \mathrm{Kim},{ }^{1}$ Mico Loretan ${ }^{2}$ and Eli M Remolona ${ }^{3}$
}

\section{Introduction}

The overriding analytical question of the global turmoil of 2007-09 is that of amplification. The turmoil started out in the floating-rate segment of the US subprime mortgage market, a relatively small part of the US mortgage market. Had the losses of US and other financial institutions been limited to those caused by defaults on subprime mortgages, the losses would have been easily absorbed and there would have been no global crisis. US and many European financial institutions, however, suffered losses on most other credit instruments as well, and so heavy were these losses that many of these institutions had to be rescued by their respective governments. Even Asia was not spared. In a region where exposures to US subprime mortgages were much smaller, borrowers' credit spreads rose in tandem with those in Europe and the United States. The question of amplification is then, how did a small problem get to be so big? In this paper, we focus on a particular aspect of that question: can one explain how the problem spread to the credit markets in Asia?

There has been no shortage of proposed amplification mechanisms. ${ }^{4}$ One mechanism is a positive feedback loop between conditions in the real economy and those in the financial system. Here, losses on mortgages led to a contraction in credit, which in turn caused the economic slowdown. The slowdown, in turn, led to further credit losses. Greenlaw et al (2008) propose a deleveraging mechanism. Given that financial institutions on average have a target leverage of ten to one, estimated losses of $\$ 500$ billion would imply that their balance sheets need to shrink by $\$ 5$ trillion, unless the institutions in question could raise new capital to cover these losses. During the crisis, the efforts to shrink balance sheets took the form of both asset sales and cut-backs in lending, both of which exacerbated the situation. Brunnermeier (2009) proposes a liquidity spiral that arises from a maturity mismatch in leveraged financing. When asset prices and liquidity fell during the crisis, the collateral values of assets held by financial institutions deteriorated. This made it difficult for them to raise funds and forced them to reduce leverage, leading to further asset price declines. Gorton (2009) focuses on a panic in the "shadow banking system", in which

1 Yonsei University, corresponding author. We thank the referee, David Orsmond, Charles Engle, Hans Genberg, Christian Upper, Philip Wooldridge, Suresh Sundaresan, and James Yetman for helpful comments and Eric Chan for excellent statistical work. This paper was written while Mico Loretan was employed at the Bank for International Settlements Representative Office for Asia and the Pacific. The views expressed here are solely those of the authors and do not necessarily reflect those of the Bank for International Settlements or the International Monetary Fund.

International Monetary Fund

3 Chief Representative, Bank for International Settlements

4 Krishnamurthy (2009) surveys a number of recent papers that have analysed amplification mechanisms. He groups these mechanisms into two broad categories. Mechanisms in the first group work primarily through balance sheets (eg, leverage, tight credit conditions, limited capital), and the second group may be described as information amplifiers, such as complexity and opaqueness of instruments and Knightian uncertainty. To be sure, the mechanisms in these two categories are not mutually exclusive. As will become clear in our discussion, our paper examines an amplification mechanism which combines elements from both categories discussed by Krishnamurthy (2009). 
financial firms de facto made runs on other financial firms by withdrawing from participation in the repo market. This led to massive deleveraging and resulted in an insolvent banking system. An aspect of this run was a sudden aversion to complex credit instruments, such as collateralised debt obligations.

In this paper, we propose that valuation losses played a large role in the amplification process and, importantly, that these losses rose because of a rise in the price of risk as well as because of an increase in risk itself. We argue that contagion to Asian borrowers occurred because the repricing of risk was a global phenomenon. We analyse valuation losses as something distinct from actual losses incurred from defaults. For major Asian borrowers valuation losses are closely linked to credit spreads on these names. The default risk of these borrowers, as we show below, did not rise very much during the crisis. However, with mark-to-market accounting, sharp increases in risk premia resulted in losses that devastated financial institutions even without any defaults occurring. ${ }^{5}$ In our story of the amplification process, the price of risk in global credit markets had declined over several years earlier this decade, thus helping to inflate what we characterise as a credit bubble. Several events between August 2007 and September 2008 then caused the price of risk to soar, serving to prick the bubble. Valuation losses have been so large precisely because the underlying bubble had become so large. ${ }^{6}$

We provide empirical evidence that shows that when valuations of credit instruments rose before the crisis and then fell during the crisis, it was not so much because of a reassessment of default risks as because of movements in credit risk premia which are closely linked to the price of credit risk. In the case of Asian borrowers (excluding Japan), credit spreads rose sharply after mid-2007 because default risk premia were driven by a global risk factor, which acted as the source of contagion. To measure credit spreads, we rely on credit default swap (CDS) contracts, which have continued to trade actively. Since these are rather simple derivative instruments, the sudden onset of aversion to more complex credit instruments did not affect their pricing drastically. ${ }^{7}$ To measure the "pure" default risk of a borrower, we rely on estimates by Moody's KMV of its expected default frequency (EDF). ${ }^{8}$ An EDF takes into account information contained in the balance sheets of the firm, the market value of its assets and liabilities, and the volatility of its asset values. As such, EDFs are forward-looking estimates of risk that take into account possible knock-on effects of slowing economic activity. To consider additional risk pricing factors, we use the principal components derived from the major CDS indices for Europe, the United States and Japan. Our econometric results suggest that credit spreads even for Asian borrowers were driven in large part by movements in global risk aversion as well as by changes in default risk. ${ }^{9}$ Our results appear to be robust to whether financial institutions are included in the sample or not.

The remainder of this paper is organised as follows. Section 2 poses the question of amplification and contagion and offers as a hypothesis the bursting of a global credit bubble.

5 A large Dutch bank was rescued by the Netherlands government in October 2008 because valuation losses had rendered it insolvent even though, according to a senior supervisor, there was "not a single penny of default".

6 Eichengreen et al (2009) also document that credit valuation losses since the onset of the crisis have been a global phenomenon and that credit valuations have moved together closely across all major regions. Chen (2008) and Chen et al (2009) also discuss evidence for changes in the price of credit risk.

7 Giesecke (2009) provides an overview of analytical issues associated with credit derivatives.

8 "EDF" is a registered trademark of Moody's KMV.

9 It is a common assumption in macroeconomic models that risk aversion is a deep parameter that is fixed. However, there is strong empirical evidence that risk aversion varies over time and indeed can be quite volatile. See, for example, Ait-Sahalia et al (2001), Bliss and Panigirtzoglou (2004) and Bekaert et al (2009). 
Section 3 specifies our analytical framework and presents stylised facts about our data on CDS spreads and EDFs for Asian names and CDS indices. Section 4 performs a preliminary analysis of the panel-dataset properties of the relationships between CDS spreads and EDFS for the Asian names. Section 5 provides our examination of what drives changes in credit spreads for major Asian borrowers. Section 6 concludes.

\section{Amplification, contagion and the credit bubble}

\subsection{Amplification and contagion}

The global financial meltdown of 2007-09 started out in the floating rate segment of the US subprime mortgage market. Total issuance in this market during 2005-07 amounted to $\$ 1$ trillion. This is relatively small compared to the total stock of US mortgage debt on one- to four-family homes of about $\$ 11$ trillion. By analysing different vintages of the subprime mortgages, Goldman Sachs (2007) estimates that default losses would total around $\$ 250$ billion. By including knock-on effects from a decline in housing prices, Greenlaw et al (2008) estimate that such default losses could reach $\$ 500$ billion. Because US financial institutions hold less than half of the subprime mortgages, their exposure to these losses would amount to an easily manageable $1 \%$ of their assets. These direct losses, however, have somehow led to losses on other credit instruments that have been far more serious. In total, these valuation losses have been so heavy that governments in the United States and in Europe have had to step in a massive way to save their financial systems from collapse. The most recent estimates by the IMF (2009, p xi) of potential write-downs for assets originated in mature markets total \$4 trillion, eight times the Greenlaw et al (2008) estimate of losses on US subprime mortgages. Government rescue packages in the Eurozone, the United Kingdom and the United States now amount to about $\$ 6$ trillion. ${ }^{10}$ The question of amplification is then: how did a small problem get to be so big?

An interesting aspect of the meltdown is how it has affected Asia. In a region where exposures to US subprime mortgages have been minimal, credit spreads for major borrowers have risen at least as much as they have for major borrowers in the United States and Europe. From the start of the crisis in August 2007 to its peak in November 2008, credit spreads for the 125 US investment-grade borrowers included in the DJ CDX IG index rose by an average of more than 170 basis points, while spreads for the 125 European borrowers in the iTraxx Europe index rose by more than 120 basis points. The credit markets seem not to have made a distinction for Asian borrowers. During the same period of the turmoil, the spreads for borrowers included in the iTraxx Asia ex-Japan index rose by more than 320 basis points.

What was behind these global co-movements in credit spreads since the onset of the crisis? Had ample liquidity in credit markets been priced in the spreads, and had liquidity for all credit instruments on these borrowers then vanished at the same time? Was the crisis a wake-up call for a global reassessment of risks, in which investors decided that they had previously badly underestimated risks and were now just correcting their mistakes? While not wishing to dismiss the potential explanatory power of these hypotheses, in this paper we examine a different mechanism, viz that the events that marked the crisis affected the risk aversion of global investors and that it was largely the resulting increase in risk aversion that led to the widening of credit spreads.

10 In terms of the amounts already spent, the rescue packages include $\$ 1.8$ trillion from the US Treasury, $\$ 1.7$ trillion from the US Federal Reserve, $\$ 680$ billion from the UK government, and $\$ 1.4$ trillion from Eurozone governments. 


\subsection{The rise and fall of the credit bubble}

We propose that the contagion in Asia as reflected in credit spreads has been part of a larger phenomenon, namely that of a global credit bubble that inflated over time and that burst during the crisis. Such a bubble would be a simple answer to the amplification question: the crisis got so big because the underlying bubble was so big. The subprime mortgage disaster was merely the pin that pricked the bubble.

We study valuation in credit markets by analysing data on credit default swaps (CDSs). One advantage of relying on CDS spreads is that they do not raise the issue of complexity, since these are rather simple derivative contracts. Since the early 2000s, these CDSs have been among the most liquid credit instruments available and seem to have maintained a modest degree of liquidity even during the crisis. ${ }^{11}$ By far the most actively traded of such instruments are the CDS index contracts, such as the DJ CDX NA IG Index for US names, the iTraxx Europe Index for European names, and the iTraxx Asia ex-Japan Index for Asian names outside Japan. Among the single-name CDS contracts, the most liquid ones have been those that are included in the indices. ${ }^{12}$ The DJ CDX NA IG Index contains 125 investment-grade US corporate names, the iTraxx Europe Index consists of 125 investment-grade European corporate names, and the iTraxx Asia ex-Japan Index is composed of 64 corporate and six sovereign names, 50 of which are investment grade and 20 high-yield. The indices are constructed as simple averages of the spreads on the constituent names.

The behaviour of average credit spreads, as measured by CDS indices, depicts the evolution of a global credit bubble since 2002. As shown in Figure 1, CDS indices started to decline in late 2002. ${ }^{13}$ At the end of May 2003, the US index stood at 77 basis points and the European index at 52 basis points. Both spread series declined further over the next four years. By May 2007, the US index had fallen to 31 basis points and the European index to 20 basis points, about two fifths of their former levels. Calculations show that this narrowing of spreads implies that the corporate bonds underlying the US index had risen in value by an average of about $2.3 \%$ and those underlying the European index by an average of about $1.6 \%$. These are very large valuation gains as investment-grade corporate bonds go, and they constitute a sign of the inflation of the global credit bubble.

The deflation of the credit bubble is generally deemed to have started on 9 August 2007, when BNP Paribas announced that it was suspending valuation of three of its funds, which had experienced large losses on their exposure to US subprime mortgages. This event triggered a widespread and prolonged decline in the amount of outstanding asset-backed commercial paper, not just in real estate-backed short-term instruments. The bubble was pricked for a second time following the weekend of 15-16 March 2008, when liquidity problems forced Bear Stearns to let itself to be taken over by JP Morgan Chase. The third and most devastating lancing of the bubble occurred after the collapse of Lehman Brothers on 15 September 2008 and of Washington Mutual a few days later. By November 2008, the US IG index had risen to 240 basis points and the European index to 180 basis points. The valuation losses implied by the widening of these spreads averaged about $10.4 \%$ for US investment-grade corporate bonds and about $8.0 \%$ for European bonds. At the end of July 2007, just before the start of the crisis, the size of the global corporate bond market as a whole stood at $\$ 48$ trillion. Assuming that the names in the CDS indices constitute a

11 Remolona and Shim (2008) analyse the market for these instruments with regard to major Asian borrowers.

12 A primary criterion for inclusion of a corporate name in a CDS index is the liquidity of its credit instruments. Membership in CDS indices is generally reviewed every six months, and names that have become less liquid are replaced by those that are more liquid.

13 Credit spreads were elevated from mid-2001 to late-2002, a period marked by several large-scale corporate accounting scandals and associated valuation losses in both equity and corporate bond markets. 
representative sample of the whole market, the implied valuation losses during the crisis would total \$4.1 trillion.

The slow growth and swift collapse of the credit bubble raise the question of what elements of valuation were involved. In this paper, we pose this question in terms of two elements that enter credit spreads, default risks and the risk premia associated with these risks. When the bubble was growing between 2002 and 2007, was it primarily because investors believed that default risks were declining, or was it because the price of default risk declined, ie because investors were willing to accept a lower compensation for bearing default risk? And, when the bubble burst, was it because perceived default risks rose suddenly, or was it mainly because the price of default risk jumped upwards?

\section{Analytical framework and data}

\subsection{Risk-neutral and physical probabilities}

We now specify a framework of analysis that allows us to distinguish between risk and the price of that risk in the valuation of credit instruments. We apply the framework particularly to credit default swaps (CDSs) and expected default frequencies (EDFs), the former representing "risk-neutral" expected losses from default and the latter "physical" default probabilities.

The CDS spread can be decomposed as: CDS spread = (Actual) Expected Loss + Default risk premium. Technically speaking, we can represent a CDS spread as a risk-adjusted (or risk-neutral) expected loss rate: $C D S_{t}=E_{t}^{Q}\left(\lambda^{Q} L\right)$, where $\lambda^{Q}$ is the risk-neutral default intensity and $L$ is loss-given-default. ${ }^{14}$ It is important to keep in mind that this expression can differ from the actual expected loss rate $E_{t}^{P}\left(\lambda^{P} L\right)$, both because $\lambda^{Q}$ can be different from the physical default intensity $\lambda^{P}$, and also because the uncertainty associated with the movement of $\lambda^{Q}$ can command a risk premium. These effects can lead to a non-trivial default risk premium. Indeed, Driessen (2005) reports that $\lambda^{Q}$, on average, exceeds $\lambda^{P}$ by a factor of about two; for BBB/Baa bonds, Amato and Remolona (2005) report a factor of four. Berndt et al (2008) find that the ratio $\lambda^{Q} / \lambda^{P}$ varies over time. Thus, a substantial part of the CDS spread variations may be due to fluctuations in a time-varying default risk premium.

In order to quantify the part of the CDS spread variation that is attributable to variations in the default risk premium, one needs to have information on the physical default probability, with which to calculate the actual expected loss. For this purpose, we take the EDF measure calculated by Moody's KMV as a proxy for the actual default probability, following the approach taken by Berndt et al (2008). As explained below, the EDFs are calculated based on a Merton-type structural model of credit risk using data on a firm's balance sheet, asset values and equity volatility. A firm's $\tau$-year EDF at time $t$ is defined as

$$
E D F_{t, \tau}=1-P(t, t+\tau) \text {, }
$$

where $P(t, t+\tau)$ is the actual (physical) probability that a surviving firm at time $t$ will also survive $\tau$ periods later. The physical default intensity $\lambda^{P}$ can be inferred from $P(t, t+\tau)$, as they are related via

\footnotetext{
14 More precisely, the CDS spread is a present-value-weighted risk-neutral expectation of $\lambda^{Q} L$.
} 


$$
P(t, t+\tau)=E_{t}^{P}\left[\exp \left(-\int_{t}^{t+\tau} \lambda^{P}(s) d s\right)\right]
$$

For relatively short horizons $\tau$, such as one year, $E D F_{t, \tau} \approx E_{t}^{P}\left(\int_{t}^{t+\tau} \lambda^{P}(s) d s\right)$. Thus, the actual expected loss rate can be approximated as the one-year EDF times the mean loss rate.

In view of the close relationship between the EDF and the physical default intensity, in our regressions of the CDS spread (or monthly change in CDS spread) we shall use the EDF (or the monthly change in the EDF) as a proxy for the variation in the amount of the default risk, and we shall include other regressors to capture the effects of variations in the price of default risk. As we explain below, the EDFs are a forward-looking measure of default risk that incorporate the near term prospects of the economy as perceived by investors.

\subsection{Data}

Our main dataset consists of monthly-frequency values, for the period from January 2005 until January 2009, for CDS spreads and EDFs for 38 corporate names from the Asia-ex-Japan region. The CDS data were obtained from Markit, and the EDF data from Moody's KMV. The names are listed in Table 1. This set is the subset of all names that were listed in one or more of the iTraxx Asia-ex-Japan CDS indices (either IG or HY) for which we were able to construct complete monthly CDS and EDF series. We focus on these 38 names because they would seem to be among the names whose default risk would be unlikely to be affected directly by troubles in the US subprime mortgage market. Moreover, EDFs are available for corporate names, while they are not for sovereign names. Among the 38 corporate names in our sample are eight financial institutions, seven telecommunication firms and four semiconductor firms. Ten of the names are from Korea, six from Singapore, five from India, four each from China and Malaysia, three each from Hong Kong and Thailand, and one each from Indonesia, the Philippines and Taiwan.

The monthly-frequency CDS data were constructed from daily CDS values, using quotes from the last available day in each month; in most cases, this was the last trading day of the month. CDS spreads are quoted in over-the-counter markets; the world's largest financial institutions are usually the main market makers in these products.

The EDF data are also for the end of each calendar month. Aspects of the design of the models that underlie the proprietary calculation methods for EDFs by Moody's KMV are discussed in Agrawal et al (2004) and Levy (2008). In general, the EDFs are calculated based on a Merton-type structural model of credit risk using data on a firm's balance sheet, asset values and equity volatility. A wide class of Merton-type models have been described and their empirical performance assessed by Huang and Huang (2002) and Eom et al (2004). According to Moody's KMV, their EDF data are used by a clear majority of major financial institutions as well as by many investment houses.

In addition, we use monthly-frequency data on the values of the iTraxx Asia ex-Japan CDS indices (both IG and HY), as well as data for the DJ CDX NA (both IG and HY) CDS indices and the iTraxx Europe CDS index. We also use the CDS spreads for the constituent names of the latter three indices.

We treat the following three dates as markers for the global financial crisis: (i) 7 August 2007, when BNP Paribas' decided to suspend valuation of three of its mutual funds; (ii) 17 March 2008, the day after the weekend when Bear Stearns was taken over by JP Morgan Chase; and (iii) 15 September 2008, the day that Lehman Brothers declared bankruptcy. As may be readily seen from the time series shown in Figure 1, spreads on the DJ CDX IG and iTraxx Europe indices rose abruptly around each of these three events. For the sake of brevity, we 
will refer to the period from August 2007 to the end of the sample in January 2009 as the crisis period, noting that the crisis of course did not consist of a single defining event.

The crisis seems to have driven an increasingly wide wedge between the time series of the average CDS spreads of the names in our sample and the time series of the average expected losses. Figure 2 shows the evolution of these time series over the sample period. Expected losses are calculated based on the EDFs and assuming a loss given default (LGD) of $0.5 .{ }^{15}$ Over the whole period, CDS spreads were much wider than expected loss rates, with the risk premium accounting for the differential. Based on the summary statistics provided in Table 2, on average the risk premium accounted for $85 \%$ of the spread and the expected loss for $15 \%$. CDS spreads began to rise from a very low level in July and August 2007 , rose rapidly in the first quarter of 2008, retraced some of that run-up during the second quarter, soared dramatically to about 750 basis points in October 2008, and remained very high over the remainder of the sample period. In contrast, expected losses did not begin to move up noticeably until September 2008, and even then they rose much less than CDS spreads moved. The challenge we face is how to explain the sharp widening of the differential between CDS rates and expected loss rates, ie the risk-premium component of CDS rates.

The major CDS indices exhibit a high degree of co-movement. Figure 3 shows the time series of the first three principal components (PCs) computed from the log-levels of the following four CDS indices: Dow Jones CDX IG, Dow Jones CDX HY, iTraxx Europe, and iTraxx Japan. The first PC explains about $98 \%$ of the total variation of the four series. As shown in Figure 3, this PC exhibits a strong time trend over the sample period: it first declines steadily, until mid-2007, and then rises sharply on balance over the remaining 18 months. In contrast, the second and third PCs (as well as the fourth, which is not shown to reduce clutter) are clearly stationary and thus describe only deviations from the dominant trend. ${ }^{16}$ The factor loadings of the logs of the individual CDS indices on the second through fourth PC do not lend themselves to any clear-cut economic interpretations. Figure 4 shows the time series of the principal components computed from the first-differenced four CDS indices; it is evident that while all PCs are stationary, the first PC is by far the most variable of the group. Figure 5 depicts the cross-sectional dispersion of EDFs and CDS spreads, averaged separately for the pre-crisis and crisis periods. In both subperiods, CDS spreads with only very few exceptions exceed EDFs considerably (there are only two points below the 45-degree line). ${ }^{17}$

Summary statistics for CDS spreads and EDFs on the 38 Asia-ex-Japan names, as well as for several CDS indices are given in Table 2 separately for the full sample period, the pre-crisis period, and the crisis period. As elsewhere in this paper, the crisis period is defined as the period from August 2007 to January 2009. Assuming an LGD of 0.5, the CDS spreads of the Asia-ex-Japan investment-grade names exceed expected losses by a factor of almost eight, while spreads of the high-yield names exceed expected losses by a factor of almost seven. This shows that by far the larger part of the spread is accounted for by the risk premium. In terms of first differences, the volatility of CDS spreads is about $60 \%$ higher than that of EDFs.

15 The factor 0.5 is close to the historical average LGD rate for Asian firms in Moody's database.

16 The fact that only one PC has a trend also implies that the five CDS index series, which are individually non-stationary, have a single cointegrating vector.

17 A separate analysis, not shown in Figure 4 to reduce clutter, suggests that the slope coefficient of a simple bivariate regression of CDS spreads on EDFs is virtually the same across the two subperiods, but that the intercept term is larger in the crisis subsample. This may suggest that investors required, for a given amount of risk, higher compensation than during the pre-crisis subperiod. 


\section{Modelling the relationship between the levels of CDS spreads and EDFs}

A natural starting point for our empirical analysis is to specify and estimate a bivariate relationship between EDFs (the independent variable) and CDS spreads (the dependent variable). Berndt et al (2008) found that a linear specification for the relationship between levels of CDS spreads and EDFs, over their sample period from 2000 to 2004, was unsatisfactory for two reasons: first, they noted the presence of heteroskedasticity in the regression errors; second, a scatterplot of pairs of CDS spreads and EDFs revealed that the bivariate relationship between the levels of the two variables tended to be concave rather than linear. To address these two issues, they took logarithms of both the dependent variable (the CDS spreads) and the regressor (the EDF rates).

We attempted to replicate the pooled double-log specification of Berndt et al (2008) for our full dataset, which consists of 38 Asia-ex-Japan corporate names during the period from January 2005 until January 2009:

$\log C D S_{i t}=a+b \log E D F_{i t}+u_{i t}$

The OLS regression results are reported in column (1) of Table 3. The estimated intercept and slope coefficients are both positive and strongly significant by ordinary statistical conventions. However, the Durbin-Watson statistic of this regression is only $0.07 .^{18}$ As was noted first by Granger and Newbold (1974) and was explained rigorously by Phillips (1986), very small values of the Durbin-Watson statistic are generally strong warning signals that the regression relationship may be spurious and the variables in the regression may therefore not be related to each other. Indeed, further tests showed that the EDFs and CDS rates of individual names, though clearly non-stationary, are not cointegrated with each other. ${ }^{19}$

Given the known presence of strong trend components in the CDS spread indices and the EDFs, the rejection of the maintained hypothesis that the simple model is specified correctly is not unexpected. We next estimated the following, expanded model:

$$
\log C D S_{i t}=a+b \log E D F_{i t}+c_{1} \log P C_{1 t}+c_{2} \log P C_{2 t}+u_{i t}
$$

where $\log P C_{k t}$ denotes, with some abuse of notation, the kth principal component of the logarithms of the CDS indices. The results of this regression are reported in column (2) of Table 3. Adding these two additional regressors unfortunately does not ameliorate the misspecification problem. We next considered the possibility that a structural break in the relationship between (log) CDS spreads and EDFs around the time of the onset of the crisis

18 The DW statistics of the individual, ie non-pooled regressions were also uniformly very low, indicating that the result for the pooled regression is not an artifact of an invalid pooling assumption. As has been noted recently by Bai et al (2009) and Breitung and Das (2008), in panel cointegration models with cross-sectional dependence generated by (usually unobserved) global stochastic trends, the least squares estimator is in general inconsistent owing to spuriousness induced by the I(1) trends. Bai et al (2009) suggest an iterative estimator to address this issue. Additional references to the panel unit root testing and cointegration literature are Gengenbach et al (2005), Levin et al (2002), and Pedroni (2004).

19 Because EDFs are estimated rather than directly observed, they contain measurement error. However, unless there are significant methodological shifts in the calculation methods of EDFs - which was not the case in our sample - it may be assumed that these measurement errors are stationary. Granger (1986, p 217) noted that if two time series are cointegrated but are observed with measurement error, the two observed series will also be cointegrated as long as the measurement errors are stationary. Therefore, (stationary) measurement errors in EDFs cannot explain our finding that EDFs and CDS rates are not cointegrated. Inference issues arising in models in which observed variables contain I(1) measurement error components are examined in more detail in Gyntelberg et al (2009). 
may give rise to this problem. However, letting each of the three slope coefficients vary across the pre-crisis and crisis periods did not solve the mis-specification problem either.

Rather than apply a direct "correction" of the serial correlation of the regression residuals, such as the Cochrane-Orcutt procedure, we chose to add the lagged endogenous variable to the basic regression; see column (3) of Table 3 . With this modification, the regression model no longer appears to be statistically mis-specified, and the R2 statistic jumps to $96 \%$. However, the numerical magnitudes of the coefficients of the constant term and the log EDFs drop to nearly zero (even though they remain statistically significantly different from zero). Put differently, the inference that the intercept and slope coefficient of the simple bivariate model are both nonzero is not robust once a better-specified model is obtained.

We also considered the possibility that the lack of robust statistical evidence for a relationship between the variables could be driven by the fact that the full sample contains both financial and non-financial firms. If the relationship is not homogeneous across these subsets of firms, spurious regression results might be generated. We re-estimated regression models (1) through (3) on the subset of non-financial firms, but the results were qualitatively very similar to those obtained for the full sample. Hence, they do not appear to be caused by heterogeneity in the composition of the sample.

These results are negative, in the sense that the statistical model using the log levels of the variables does not let us draw robust conclusions regarding the relationship between CDS spreads and EDFs (and hence the difference between these two series). Nevertheless, these findings suggest that cross-sectional relationships between the two series are dominated by time trends in the series. This is a useful result, as it motivates us to study the relationship between the variables in a first-differenced model, the subject of the next section.

\section{What drives changes in credit spreads?}

\subsection{Variables}

To explain how credit spreads narrowed between 2002 and 2007 and how they widened afterwards, we analyse first differences in CDS spreads on the 38 names in the iTraxx Asia ex-Japan Index for which we have good data. We also analyse a subsample of 31 names that excludes financial firms. Our explanatory variables consist of a measure of default risk and of variables representing risk pricing factors. For changes in default risk, we use first differences in EDFs for each of our 38 names. For risk pricing factors, we extract the principal components from the first differences of the four CDS indices (two from the United States, one each for Europe and Japan).

\subsection{Principal components}

Before we report the results of our regression analysis, it is useful to discuss the main properties of the principal components (PCs) that we constructed from the first differences of the four CDS indices. ${ }^{20}$ As shown in Table 4, the first PC explains about $80 \%$ of the movements of the four CDS indices. An analysis of its loadings and time series properties suggests that it is a global risk pricing factor: it has roughly equal loadings on all four CDS indices, it is highly correlated with all four stock market index returns shown in Table 4, and it is also (albeit with the opposite sign) highly correlated with changes in equity market volatility

20 Longstaff et al (2008) provide a useful summary of the properties of the principal components obtained from sovereign CDS spreads. 
and fluctuations in the steepness of the US Treasury yield curve. The second PC explains an additional $13 \%$ of the variance of the movements in the indices, and its loadings and its higher correlations with changes in the spread between three-month OIS and eurodollar rates suggest that it is a credit and liquidity crisis risk pricing factor. The third PC, which explains about $6 \%$ of the movements in the indices, appears to be a Japan-specific risk pricing factor. The fourth PC contributes a negligible amount to explaining the total variance. ${ }^{21}$

\subsection{Estimates}

Our basic estimating equations are

$$
\begin{aligned}
& \Delta C D S_{i t}=b_{0}+b_{1} \Delta E D F_{i t}+u_{i t} \\
& \Delta C D S_{i t}=b_{0}+b_{1} \Delta E D F_{i t}+b_{2} \Delta P C_{1 t}+b_{3} \Delta P C_{2 t}+b_{4} \Delta P C_{3 t}+u_{i t},
\end{aligned}
$$

where $\Delta$ denotes first differences, the subscript i the ith name in the panel, the subscript $\mathrm{t}$ the observation month, and $\triangle P C_{k t}$ (again with some abuse of notation) the k-th principal component of the first-differenced CDS indices. The first equation uses only the EDF variable as an explanatory variable. The second includes the first three PCs of the first-differenced CDS indices. We fit the equations to data involving a cross-section of 38 names and a time series of 48 months, running from February 2005 to January $2009 .^{22}$

The panel regression results show that fluctuations in the risk pricing factors as well as reassessments of default risk have been important drivers of changes in CDS spreads. As reported in columns 2 of Table 5, the EDF variable as well as the first three principal components are all statistically significant at conventional confidence levels. Notably, the fitted model that only has the EDFs as explanatory variables has an adjusted R2 of $24 \%$. Once the principal components are included, the adjusted R2 jumps to 39\%. The DurbinWatson statistics are close to 2, suggesting that taking first differences of the data indeed succeeded in eliminating the trend components noted in Section 4. The onset of crisis seems not to change the relationships. ${ }^{23}$

The coefficients of some of the explanatory variables are estimated rather tightly, and it is interesting to interpret their economic significance. In the more comprehensive model, the coefficients of the EDF variable and of the first three principal components are estimated with very small standard errors. In the case of the EDF variable, a 100 basis-point move, ceteris paribus, on average results in a 72 basis-point change in the spread in the same direction. This is a surprisingly weak effect, given that EDFs are always much smaller and less volatile than the corresponding CDS spreads. Put another way, a one standard-deviation move in the physical probability of default on average leads to a change in the risk-neutral probability of only 0.42 of its standard deviation.

The estimated coefficients of the first three principal components are smaller in absolute value than the coefficient on the EDF variable. However, the risk pricing factors are also

21 Goyal et al (2008) discuss methods for estimating principal components that are common to variables across groups of variables, as well as specific to individual groups of variables. In future work, we plan to employ their methodology to test for commonalities among the principal components of each of the three groups.

22 Relative to the regressions reported in Section 4, the use of first-differenced data causes the "loss" of 1 observation in the time-series dimension.

23 When we added dummy variables for the crisis period, both as intercept terms and as interactive variables, the adjusted R2 did not rise substantially, and the augmented model was characterised by severe multicollinearity among some of the regressors. 
more volatile than the EDF variable. Indeed, a one standard-deviation move in the first principal component leads, ceteris paribus, to a change in the CDS spread of an Asian name by 0.32 of its standard deviation. This is of the same order of magnitude as the economic effect of changes in EDFs, and it is an effect that is neglected in the literature on the crisis. Similarly, a one standard-deviation move in the second PC leads on average to a change in the CDS spread by 0.12 of its standard deviation, a not insignificant economic effect.

Note that because these results are based on the economic significance of the coefficients, they do not hinge on us having access to the precise measures of default risk that were on the minds of investors. Our inference requires only that we have an unbiased measure of default risk. ${ }^{24}$

Our results appear to be robust to a number of specification choices. For instance, because EDF estimates are likely to be less reliable for financial institutions, which tend to have very high leverage, we ran the same regressions for only the subsample of 31 Asian names that are non-financial firms. As shown in columns 3 and 4 of Table 5, we do get a slightly better goodness of fit when financial firms are excluded. However, the qualitative results do not change. We also interacted our explanatory variables with dummy variables that represent various phases of the crisis. The interaction terms do not result in statistically significant coefficients, suggesting that the crisis did not change the relationships among the variables. If the liquidity of CDS contracts did change because of the crisis, this did not seem to discernibly affect the price determination process.

Summing up, our analysis shows that valuations in credit markets do react consistently to reassessments of default risk. However, this reaction is not the only important one. Instead, changes in valuations appear to be driven also by changes in the price of default risk, and this price seems to be affected by both global and region-specific fluctuation in investors' risk aversion. The idea that risk aversion is an important determinant of credit spreads is not entirely new. It is consistent with the results of Tang and Yan (2009), for example. They find that at the level of the market, a variable representing investor sentiment is the most important determinant of credit spreads. Moreover, at the level of individual firms, they identify implied volatility, which should incorporate the influence of risk aversion, as "the most significant determinant of default risk".

\section{Conclusion}

A striking feature of the 2007-09 global financial meltdown is the fact that credit spreads widened sharply for everyone, even for large borrowers in Asia who were far removed from the problems of the US subprime mortgage market. As a consequence, valuation losses on credit instruments were massive, dwarfing losses from actual defaults. We propose that these valuation losses played an important role in the amplification of the crisis. While it could be argued that the decline in valuations simply reflected the knock-on effects on default risk of an anticipated economic slowdown, our results do not bear this out. In this paper, we take account of such knock-on effects on large Asian borrowers and still find strong effects on spreads that seem to stem from shifts in risk aversion, both of global investors and investors with a regional focus.

To analyse valuation, we rely on spreads on CDS contracts, which are rather simple derivative instruments that continued to trade even during the crisis. To account for the

24 Because default probabilities are not observable, one cannot test this unbiasedness hypothesis directly. However, KMV aims to have EDFs equal actual default frequencies over suitably chosen longer time intervals. 
knock-on effects on default risk, we rely on EDFs, which are estimates of default probabilities that exploit the forward-looking nature of stock prices. To account for global and regional risk aversion, we extract principal components from the movements of various CDS indices comprising US, European and Asian names. We then regress monthly first-differences in CDS spreads for a cross-section of Asian names on monthly first-differences in their respective EDFs as well as the principal components. We find statistically and economically significant effects of EDFs and principal components that represent risk aversion. The results suggest that shifts in risk aversion as well as reassessments of risk drive valuations of credit instruments. Moreover, there is an important global component to risk aversion, and a rise in such risk aversion would naturally be a source of contagion.

These results do not just apply to the period of the crisis of 2007-09. They account for the narrowing of credit spreads before the onset of the crisis as well as for the widening of spreads around each of the various events that marked the crisis. We find no change in the price determination relationships between the pre-crisis and crisis periods. Our results are consistent with the notion that the global turmoil was an accident waiting to happen. Between 2002 and 2007, as risk appetites in credit markets grew, a large credit bubble developed. The troubles in the US subprime mortgage market were merely the trigger for the crisis. If not for these mortgages, something else would inevitably have pricked the bubble. And the crisis became so large because the underlying bubble was so large. We conclude that periods of rising credit bubbles are to a large extent periods of declining risk aversion. When a bubble bursts, it bursts because risk aversion suddenly jumps. To better understand the formation of bubbles and their destruction would require a better understanding of the behaviour of investor risk aversion. 
Table 1

Asian names, by economy and industry

\begin{tabular}{|c|c|c|}
\hline Company & Economy & Industry \\
\hline Bank of China Ltd. & China & Banking \\
\hline CITIC Resources Holdings Ltd. & China & Diversified \\
\hline CNOOC Ltd. & China & Oil and gas \\
\hline Xinao Gas Holdings Ltd. & China & Energy \\
\hline Hutchison Whampoa Ltd. & Hong Kong & Diversified \\
\hline PCCW HKT TEL Ltd. & Hong Kong & Telecommunication \\
\hline Road King Infrastructure Ltd. & Hong Kong & Infrastructure \\
\hline Bank of India & India & Banking \\
\hline ICICl Bank & India & Banking \\
\hline Reliance Communications Ltd. & India & Telecommunication \\
\hline Reliance Industries Ltd. & India & Oil refining \\
\hline Tata Motors Ltd. & India & Automobile \\
\hline PT Indosat Terbuka & Indonesia & Telecommunication \\
\hline Hana Bank & Korea & Banking \\
\hline Hynix Semiconductor Incorp. & Korea & Semiconductor \\
\hline Hyundai Motor Co. & Korea & Automobile \\
\hline Industrial Bank Korea & Korea & Banking \\
\hline KT Corp. & Korea & Telecommunication \\
\hline Korea Electric Power Corp. & Korea & Electricity \\
\hline POSCO & Korea & Steel \\
\hline Samsung Electronics Co. Ltd. & Korea & Electronics \\
\hline SK Energy Co. Ltd. & Korea & Oil refining \\
\hline SK Telecom Co. Ltd. & Korea & Telecommunication \\
\hline Genting Bhd. & Malaysia & Casino/hotel \\
\hline IOI Corp. Bhd. & Malaysia & Agriculture \\
\hline Telekom Malaysia Bhd. & Malaysia & Telecommunication \\
\hline Tenaga Nasional Bhd. & Malaysia & Electricity \\
\hline Philippines Long Distance Telephone & Philippines & Telecommunication \\
\hline Capitaland Ltd. & Singapore & Real Estate \\
\hline Chartered Semiconductor Manufacturing Ltd. & Singapore & Semiconductor \\
\hline China Fishery Group Ltd. & Singapore & Fishery \\
\hline Noble Group Ltd. & Singapore & Diversified \\
\hline Stats Chippac Ltd. & Singapore & Semiconductor \\
\hline United Overseas Bank & Singapore & Banking \\
\hline Cathay Financial Holdings Co. Ltd. & Taiwan & Insurance \\
\hline Aromatic Thailand Public Co. Ltd. & Thailand & Petrochemicals \\
\hline PTT Aromatics and Refining Pub. Co. Ltd. & Thailand & Oil refining \\
\hline PTT Public Co. Ltd. & Thailand & Oil and gas \\
\hline
\end{tabular}

Source: Bloomberg. 
Table 2

Summary statistics for CDS spreads and EDFs

\begin{tabular}{|c|c|c|c|c|c|c|}
\hline & \multicolumn{2}{|c|}{ Full sample $^{1}$} & \multicolumn{2}{|c|}{ Pre-crisis period $^{2}$} & \multicolumn{2}{|c|}{ Crisis period $^{3}$} \\
\hline & Mean & $\begin{array}{l}\text { Standard } \\
\text { deviation }\end{array}$ & Mean & $\begin{array}{l}\text { Standard } \\
\text { deviation }\end{array}$ & Mean & $\begin{array}{l}\text { Standard } \\
\text { deviation }\end{array}$ \\
\hline \multicolumn{7}{|l|}{ Levels } \\
\hline \multicolumn{7}{|l|}{ CDS spreads } \\
\hline Asia ex-Japan: 38 names & 178.0 & 291.7 & 69.1 & 66.4 & 328.4 & 397.0 \\
\hline 26 IG names & 98.0 & 128.7 & 40.1 & 24.4 & 188.5 & 167.5 \\
\hline $12 \mathrm{HY}$ names & 380.8 & 449.3 & 157.8 & 75.3 & 608.2 & 547.8 \\
\hline \multicolumn{7}{|l|}{ EDFs } \\
\hline Asia ex-Japan: 38 names & 38.3 & 144.6 & 16.4 & 28.1 & 68.4 & 217.1 \\
\hline 26 IG names & 15.0 & 29.7 & 11.1 & 11.3 & 21.2 & 44.8 \\
\hline $12 \mathrm{HY}$ names & 97.2 & 258.8 & 32.8 & 49.8 & 162.8 & 352.8 \\
\hline \multicolumn{7}{|l|}{ CDS index spreads } \\
\hline DJ CDX NA IG & 76.4 & 54.3 & 44.3 & 10.5 & 131.5 & 55.3 \\
\hline DJ CDX NA HY & 483.2 & 275.9 & 335.7 & 62.2 & 737.3 & 316.2 \\
\hline iTraxx Europe & 56.3 & 42.7 & 32.0 & 7.4 & 98.2 & 45.9 \\
\hline iTraxx Japan & 65.3 & 81.8 & 25.0 & 4.7 & 134.7 & 103.8 \\
\hline iTraxx Asia ex-Japan IG & 85.0 & 98.2 & 34.4 & 6.9 & 172.0 & 120.3 \\
\hline iTraxx Asia ex-Japan HY & 372.2 & 344.3 & 199.9 & 42.7 & 668.8 & 429.2 \\
\hline \multicolumn{7}{|l|}{ First differences } \\
\hline \multicolumn{7}{|l|}{ CDS spreads } \\
\hline Asia ex-Japan: 38 names & 14.2 & 103.1 & 0.1 & 15.0 & 33.7 & 156.1 \\
\hline 26 IG names & 7.8 & 53.4 & 0.2 & 8.0 & 19.5 & 83.5 \\
\hline $12 \mathrm{HY}$ names & 30.6 & 173.3 & -0.3 & 26.9 & 62.2 & 241.1 \\
\hline \multicolumn{7}{|l|}{ EDFs } \\
\hline Asia ex-Japan: 38 names & 4.3 & 58.9 & -0.8 & 7.9 & 11.4 & 89.9 \\
\hline 26 IG names & 0.9 & 12.5 & -0.5 & 3.5 & 3.1 & 19.3 \\
\hline $12 \mathrm{HY}$ names & 13.1 & 108.5 & -1.5 & 14.6 & 27.9 & 152.2 \\
\hline \multicolumn{7}{|l|}{ CDS index spreads } \\
\hline DJ CDX NA IG & 3.2 & 18.5 & 1.2 & 8.4 & 6.5 & 28.4 \\
\hline DJ CDX NA HY & 22.9 & 95.4 & 6.6 & 49.0 & 50.0 & 140.7 \\
\hline iTraxx Europe & 2.6 & 14.2 & 0.6 & 5.9 & 6.0 & 21.8 \\
\hline iTraxx Japan & 7.0 & 25.6 & 0.5 & 4.6 & 17.7 & 39.8 \\
\hline iTraxx Asia ex-Japan IG & 6.4 & 31.6 & 0.1 & 5.0 & 16.9 & 50.3 \\
\hline iTraxx Asia ex-Japan HY & 22.4 & 124.9 & -1.3 & 25.1 & 61.9 & 198.6 \\
\hline
\end{tabular}


Table 3

Regression results for log-log model

Dependent variable: $\log _{\text {CDS }}$ it . Full sample (38 names).

\begin{tabular}{|c|c|c|c|}
\hline & (1) & (2) & (3) \\
\hline \multirow[t]{2}{*}{ Constant } & $3.274^{\star * *}$ & $3.697^{\star * \star}$ & $0.353^{\star \star \star}$ \\
\hline & $(0.052)$ & $(0.041)$ & $(0.033)$ \\
\hline \multirow[t]{2}{*}{$\log _{E D F}$ it } & $0.495^{\star \star *}$ & $0.299 * \star \star$ & $0.021 * \star \%$ \\
\hline & (0.052) & (0.015) & (0.006) \\
\hline \multirow[t]{2}{*}{$\log P C 1_{t}$} & - & $0.338^{\star \star \star}$ & $0.062^{\star \star \star}$ \\
\hline & & $(0.009)$ & (0.004) \\
\hline \multirow[t]{2}{*}{$\log P C 2_{t}$} & - & 0.192 & $-0.235^{\star \star \star}$ \\
\hline & & $(0.088)$ & $(0.030)$ \\
\hline \multirow[t]{2}{*}{$\log \operatorname{CDS}_{\mathrm{i}, \mathrm{t}-1}$} & - & - & $0.918^{\star \star \star}$ \\
\hline & & & $(0.008)$ \\
\hline R-squared & 0.306 & 0.626 & 0.961 \\
\hline Adjusted R-squared & 0.305 & 0.625 & 0.960 \\
\hline S.E. of regression & 0.956 & 0.702 & 0.230 \\
\hline $\begin{array}{l}\text { Durbin-Watson } \\
\text { statistic }\end{array}$ & 0.072 & 0.077 & 2.073 \\
\hline
\end{tabular}

Sample period: Jan. 2005-Jan. 2009. Standard errors shown in parentheses. ***, **, and * indicates significance at $1 \%, 5 \%$, and $10 \%$ levels.

Sources: Markit; Moody's Investors Services; authors' estimates. 
Table 4

Properties of the first three principal components of the four first-differenced CDS indices

\begin{tabular}{|c|c|c|c|}
\hline & $\triangle \mathrm{PC1}$ & $\triangle \mathrm{PC} 2$ & $\triangle \mathrm{PC} 3$ \\
\hline \multicolumn{4}{|l|}{ Factor loadings } \\
\hline iTraxx Japan & 0.497 & -0.375 & 0.747 \\
\hline iTraxx Europe & 0.479 & 0.697 & 0.187 \\
\hline DJ CDX NA IG & 0.530 & 0.244 & -0.443 \\
\hline DJ CDX NA HY & 0.493 & -0.560 & -0.459 \\
\hline Fraction of variance explained & 0.797 & 0.127 & 0.062 \\
\hline \multicolumn{4}{|l|}{ Correlations with economic variables } \\
\hline$\Delta \mathrm{VIX}$ & 0.6268 & -0.1041 & -0.0876 \\
\hline$\Delta(3 \mathrm{mo}-10 \mathrm{yr}$ term spread) & 0.3579 & -0.1917 & 0.0118 \\
\hline$\Delta$ (3mo US dollar Libor-OIS spread) & 0.0739 & 0.2199 & -0.0576 \\
\hline$\Delta(\log$ S\&P500) & -0.8002 & 0.1910 & -0.0985 \\
\hline$\Delta$ (log Nikkei) & -0.6540 & 0.1492 & -0.2234 \\
\hline$\Delta(\log \mathrm{MSCl}$ World $)$ & -0.7407 & 0.2191 & -0.1335 \\
\hline$\Delta$ (log MSCl Asia Japan) & -0.6373 & 0.1903 & -0.2018 \\
\hline
\end{tabular}


Table 5

Regression results for first-differences model

Dependent variable: $\Delta \mathrm{CDS}_{\mathrm{t}}\left(=\mathrm{CDS}_{\mathrm{t}}-\mathrm{CDS}_{\mathrm{t}}-1\right)$

\begin{tabular}{|c|c|c|c|c|}
\hline & \multicolumn{2}{|c|}{$\begin{array}{l}\text { Full sample } \\
\text { (38 names) }\end{array}$} & \multicolumn{2}{|c|}{$\begin{array}{l}\text { Non-financials only } \\
\text { (31 names) }\end{array}$} \\
\hline & (1) & (2) & (3) & (4) \\
\hline Constant & $\begin{array}{l}10.491^{\star \star \star} \\
(2.378)\end{array}$ & $\begin{array}{l}9.761^{\star \star \star} \\
(2.122)\end{array}$ & $\begin{array}{l}11.377^{\star \star \star} \\
(2.707)\end{array}$ & $\begin{array}{l}10.588^{\star \star *} \\
(2.419)\end{array}$ \\
\hline$\Delta \mathrm{EDF}_{\mathrm{t}}$ & $\begin{array}{l}0.863^{\star * *} \\
(0.040)\end{array}$ & $\begin{array}{l}0.724^{\star * *} \\
(0.038)\end{array}$ & $\begin{array}{l}0.855^{\star \star \star} \\
(0.042)\end{array}$ & $\begin{array}{l}0.714^{\star \star *} \\
(0.039)\end{array}$ \\
\hline$\Delta P C 1_{t}$ & - & $\begin{array}{l}0.173^{\star \star \star} \\
(0.012)\end{array}$ & - & $\begin{array}{l}0.187^{\star \star \star} \\
(0.013)\end{array}$ \\
\hline$\triangle P C 2_{t}$ & - & $\begin{array}{l}0.134^{\star \star \star} \\
(0.029)\end{array}$ & & $\begin{array}{l}0.138^{\star \star \star} \\
(0.032)\end{array}$ \\
\hline$\triangle P C 3_{t}$ & & $\begin{array}{l}0.399 * \star \star \\
(0.041)\end{array}$ & & $\begin{array}{l}0.433^{\star \star \star} \\
(0.046)\end{array}$ \\
\hline R-squared & 0.243 & 0.388 & 0.257 & 0.408 \\
\hline Adjusted R-squared & 0.242 & 0.386 & 0.256 & 0.406 \\
\hline S.E. of regression & 89.858 & 80.769 & 93.718 & 83.733 \\
\hline Durbin-Watson & 2.148 & 2.287 & 2.103 & 2.261 \\
\hline
\end{tabular}

Sample period: Feb. 2005-Jan. 2009. Standard errors shown in parentheses. ***, **, and * indicates significance at $1 \%, 5 \%$, and $10 \%$ levels.

Sources: Markit; Moody's Investors Services; authors' estimates. 
Figure 1

\section{CDS indices}

In basis points

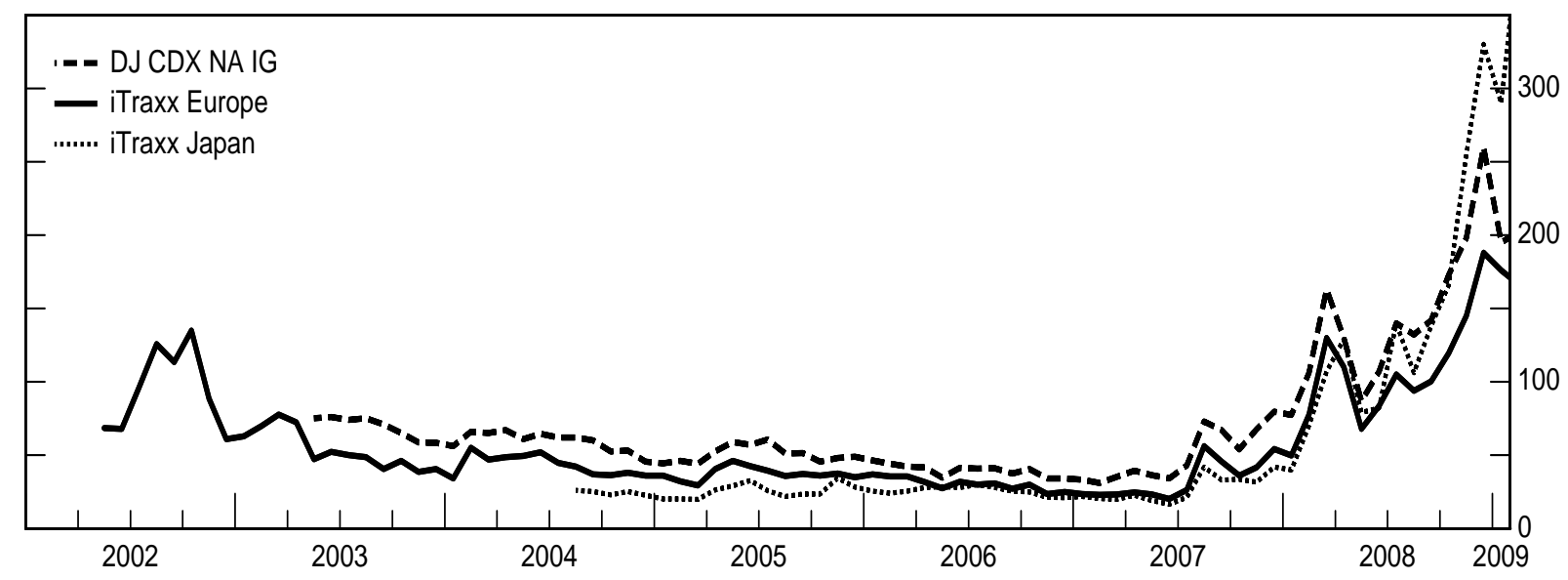

CDS indices are equal-weighted averages of the spreads on the underlying five-year CDS contracts.

Source: JPMorgan Chase.

Figure 2

CDS spreads and expected losses

Averages over 38 Asia-ex-Japan names, in basis points

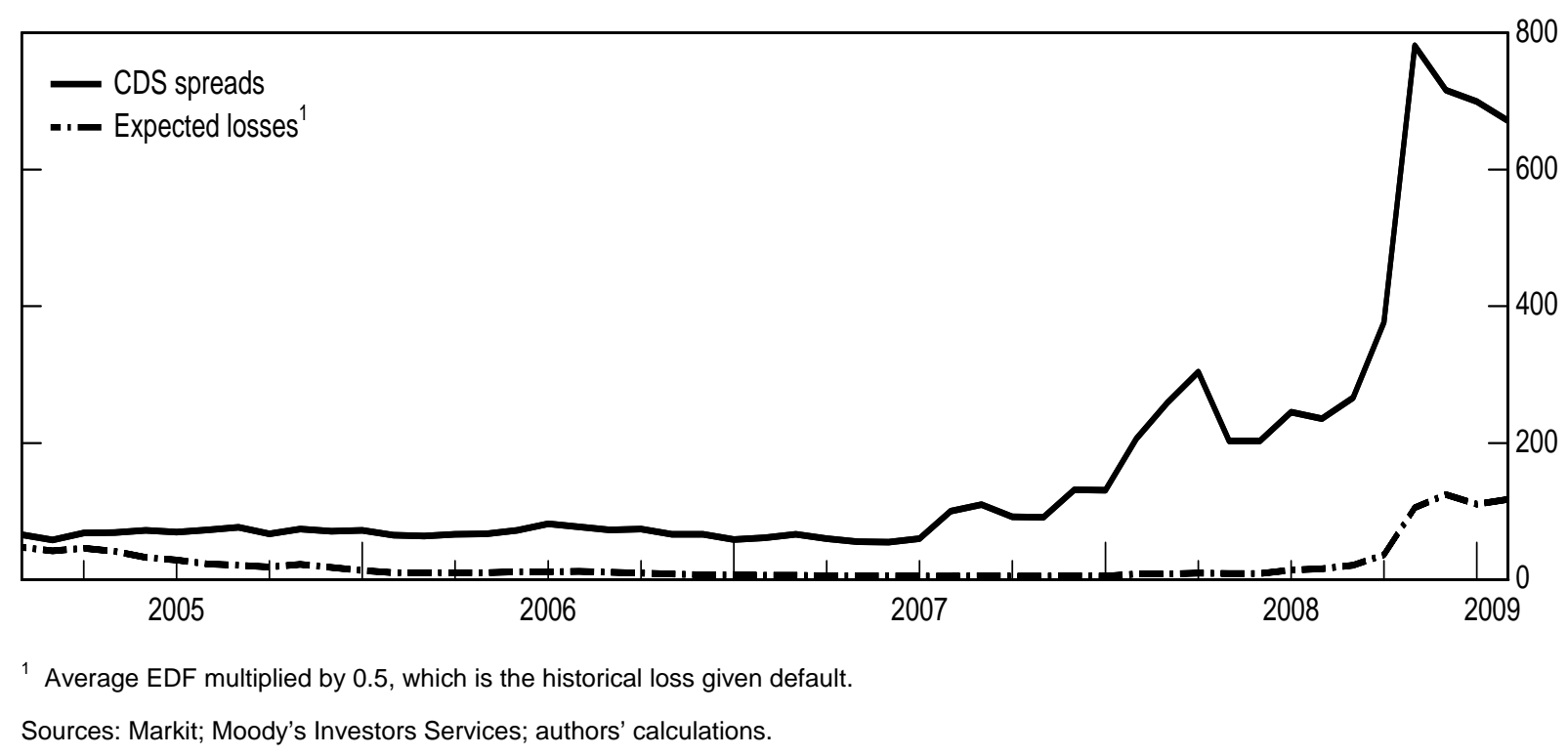


Figure 3

Principal components of logarithms of four CDS indices ${ }^{1}$

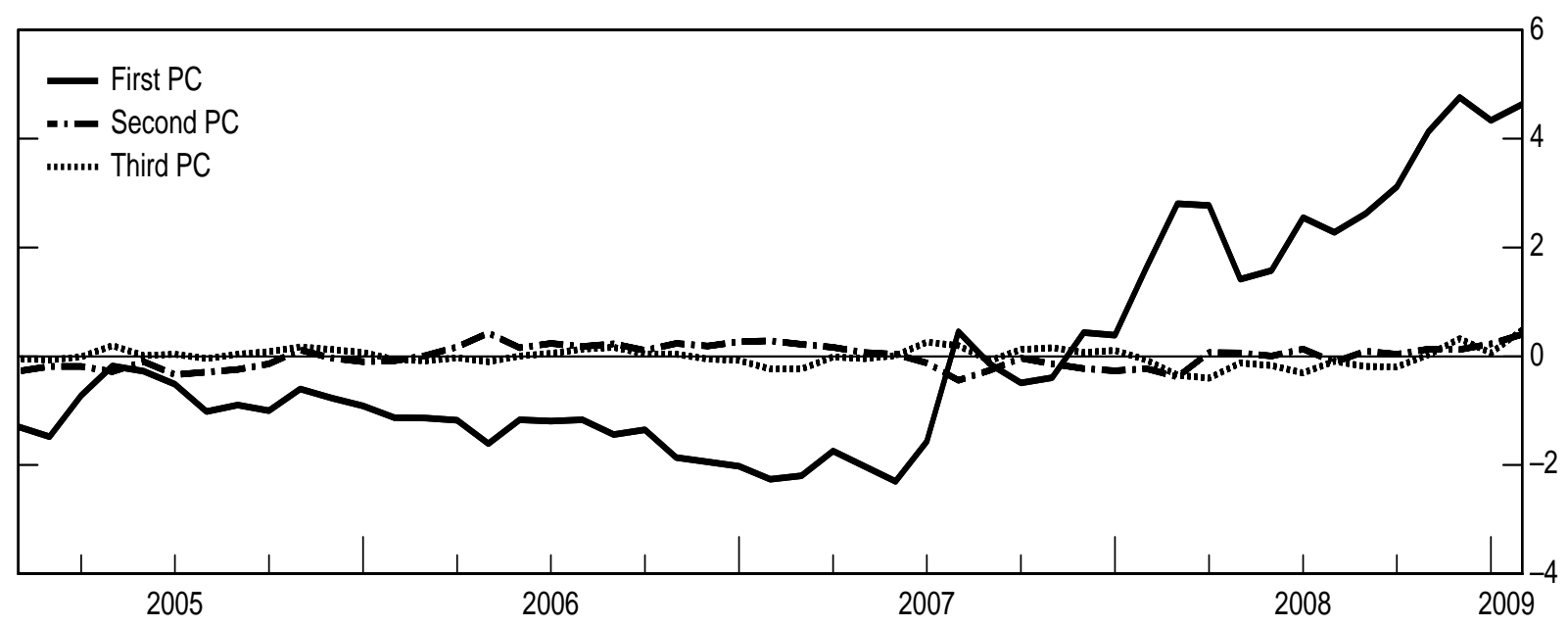

${ }^{1}$ The four CDS indices are: US CDS NA IG, US CDX NA HY, iTraxx Europe, and iTraxx Japan.

Sources: JPMorgan Chase; authors' calculations.

Figure 4

Principal components of the first differences of four CDS indices ${ }^{1}$

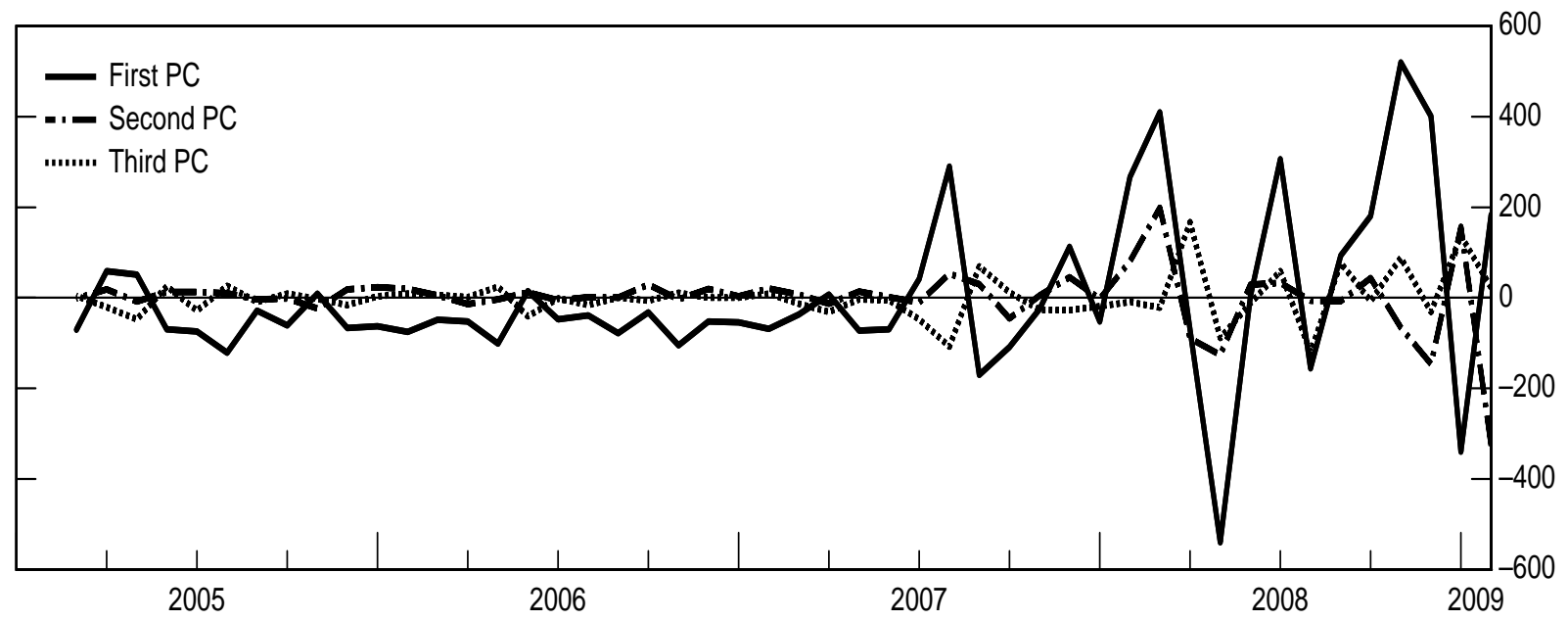

${ }^{1}$ The four CDS indices are: US CDX NA IG, US CDX NA HY, iTraxx Europe, and iTraxx Japan.

Sources: JPMorgan Chase; authors' calculations. 
Figure 5

CDS spreads and EDFs, by Asia-ex-Japan name

Pre-crisis and crisis period averages shown separately In base-10 logarithms of basis points

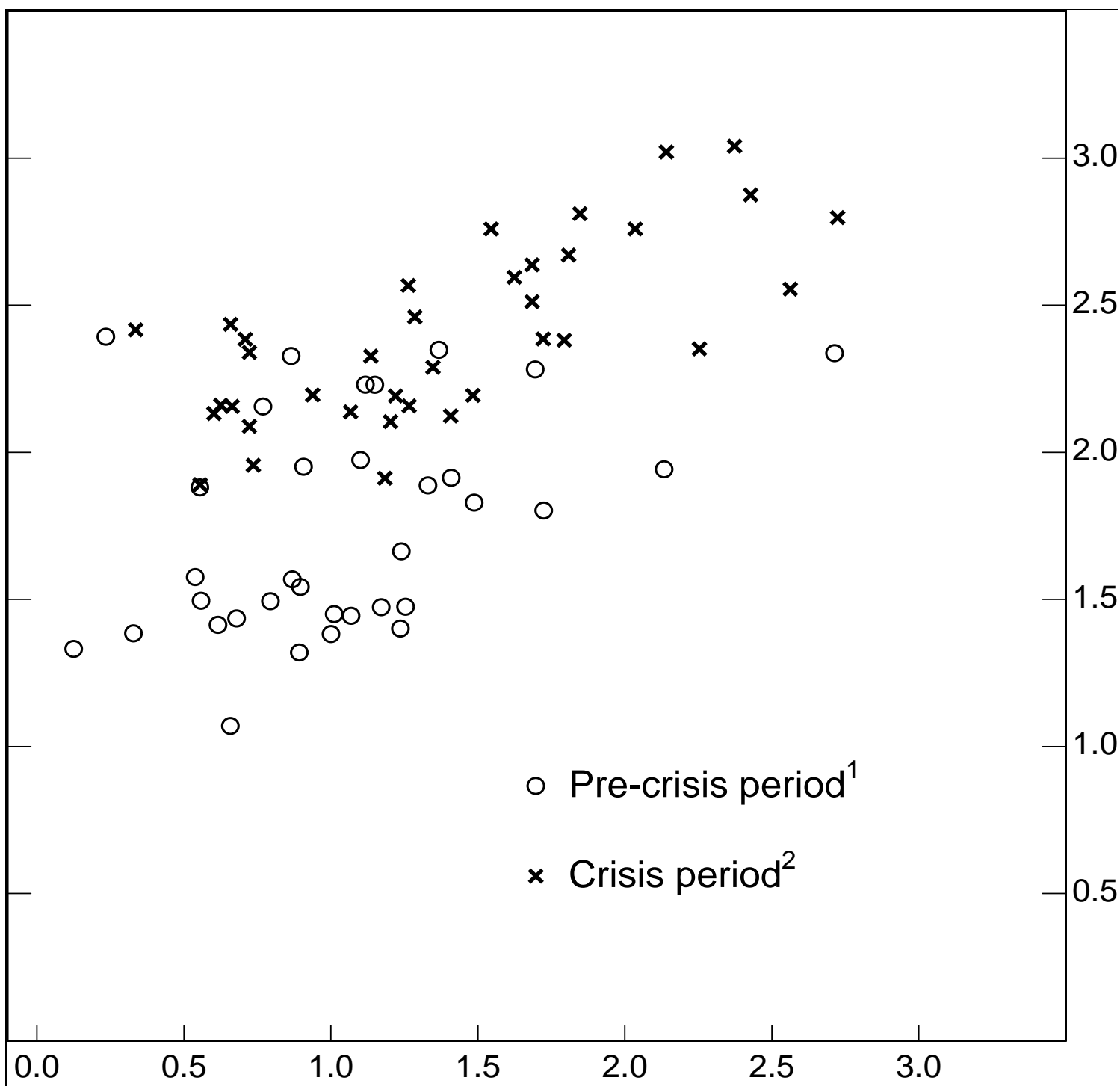

Horizontal axis: EDFs; Vertical axis: CDS spreads

1 January 2005 to July 2007. ${ }^{2}$ August 2007 to January 2009.

Sources: Markit; Moody's Investors Services. 


\section{References}

Agrawal, D., Arora, N., Bohn, J., 2004. Parsimony in practice: An EDF-based model of credit spreads. Manuscript, Moody's KMV.

Aït-Sahalia, Y., Wang, Y., Yared, F., 2001. Do option markets correctly price the probabilities of movement of the underlying asset? Journal of Econometrics 102, 67-110.

Amato, J. D., Remolona, E. M., 2005. The pricing of unexpected credit losses. BIS Working Paper No. 190.

Bai, J., Kao, C., Ng, S., 2009. Panel cointegration with global stochastic trends. Journal of Econometrics 149, 82-99.

Bekaert, G., Hoerova, M., Scheicher, M., 2009. What do asset prices have to say about risk appetite and uncertainty? ECB Working Paper No. 1037.

Berndt, A., Douglas, R., Duffie, D., Ferguson, M., Schranz, D., 2008. Measuring default risk premia from default swap rates and EDFs. Manuscript, Tepper School of Business, Carnegie Mellon University.

Bliss, R., Panigirtzoglou, N., 2004. Option-implied risk aversion estimates. Journal of Finance 59, 407-46.

Breitung, J., Das, S., 2008. Testing for unit roots in panels with a factor structure. Econometric Theory 24, 88-108.

Brunnermeier, M. K., 2009. Deciphering the liquidity and credit crunch 2007-08. Journal of Economic Perspectives 23, 77-100.

Chen, H., 2008. Macroeconomic conditions and the puzzles of credit spreads and capital structure. Manuscript, MIT Sloan School of Management.

Chen, L., Collin-Dufresne, P., Goldstein, R.S., 2009. On the relation between the credit spread puzzle and the equity premium. Review of Financial Studies, forthcoming.

Driessen, J., 2005. Is default event risk priced in corporate bonds? Review of Financial Studies 18, 165-95.

Eichengreen, B., Mody, A., Nedeljkovic, M., Sarno, L., 2009. How the subprime crisis went global: evidence from bank credit default swap spreads. NBER Working Paper No. 14904.

Eom, Y. H., Helwege, J., Huang, J.-Z., 2004. Structural models of corporate bond pricing: An empirical analysis. Review of Financial Studies 17, 499-544.

Gengenbach, C., Palm, F. C., Urbain, J.-P., 2005. Panel cointegration testing in the presence of common factors. Manuscript, Department of Quantitative Economics, University of Maastricht.

Giesecke, K., 2009. An overview of credit derivatives. Manuscript, Stanford University.

Goldman Sachs, 2007. The subprime issue: A global assessment of losses, contagion and strategic implications. November 20.

Gorton, G., 2009. Slapped in the face by the invisible hand: Banking and the panic of 2007. Manuscript, Yale University.

Goyal, A., Pérignon, C., Villa, C., 2008. How common are common return factors across the NYSE and Nasdaq? Journal of Financial Economics 90, 252-71.

Greenlaw, D., Hatzius, J., Kashyap, A.K., Shin, H.S., 2008. Leveraged losses: lessons from the mortgage market meltdown, US Monetary Policy Forum Report No. 2.

Granger, C. W. J., 1986. Developments in the study of cointegrated economic variables. Oxford Bulletin of Economics and Statistics 48, 213-28. 
Granger, C. W. J., Newbold, P., 1974. Spurious regressions in econometrics. Journal of Econometrics 2, 111-120.

Gyntelberg, J., Loretan, M., Subhanij, T., Chan, E., 2009. Private information, stock markets, and exchange rates. BIS Working Paper No. 271.

Huang, J.-Z., Huang, M., 2002. How much of the corporate-Treasury spread is due to credit risk? NYU Working Paper No. FIN-02-040.

IMF, 2009. Global Financial Stability Report April 2009: Responding to the financial crisis and measuring systemic risks. Washington DC: International Monetary Fund.

Krishnamurthy, A., 2009. Amplification mechanisms in liquidity crises. NBER Working Paper No. 15040, June.

Levin, A., Lin, C.-F., Chu C.-S. J., 2002. Unit roots in panel data: Asymptotic and finitesample properties. Journal of Econometrics 108, 1-24.

Levy, A. 2008. An overview of modeling credit portfolios. Manuscript, Moody's KMV.

Longstaff, F., Pan, J., Pedersen, L.H., Singleton, K.J., 2008. How sovereign is sovereign credit risk? Manuscript, UCLA Anderson School of Business.

Phillips, P.C.B., 1986. Understanding spurious regressions in econometrics. Journal of Econometrics 33, 311-40.

Pedroni, P., 2004. Panel cointegration: asymptotic and finite sample properties of pooled time series tests with an application to the PPP hypothesis. Econometric Theory 20, 597-625.

Remolona, E.M., Shim, I., 2008. Credit derivatives and structured credit: The nascent markets of Asia and the Pacific. BIS Quarterly Review, June, 57-65.

Tang, D.Y. and H. Yan, 2009. Market conditions, default risk and credit spreads. Journal of Banking and Finance, forthcoming. 